\title{
Una filosofía en acción: Carl Einstein y Die Fabrikation der Fiktionen
}

\section{A philosophy in action: Carl Einstein and Die Fabrikation der Fiktionen}

\author{
José María DE LUELMO JAREÑO \\ Universitat Politècnica de València
}

Recibido: 06-11-2014

Aceptado: 07-06-2015

\section{Resumen}

Si Carl Einstein sigue siendo de por sí una figura marginal dentro de la cultura alemana, su obra Die Fabrikation der Fiktionen permanece desatendida incluso entre sus estudiosos pese a contener valiosísimas claves para entender el cruce entre filosofía y política que caracteriza a buena parte del pensamiento europeo del siglo XX. Así las cosas, tras una parte inicial donde se dibuja a grandes rasgos la personalidad del autor y se toma el pulso a sus últimas ideas y acciones, el artículo despliega un examen detenido de la obra, realizando en primera instancia un cotejo de las distintas interpretaciones que de ella se han venido haciendo, y llevando después a cabo una nueva lectura de sus principales ideas fuerza -el conflicto entre Realität y Wirklichkeit o el propio concepto de Fiktion - y una valoración de la empresa einsteiniana mediante su contraste con ciertas obras de pensadores coetáneos como Siegfried Kracauer y Paul Nizan.

Palabras clave: aparato ficcional, dialéctica, intelectualidad, materialismo, realidad, revolución conservadora, vanguardia.

\begin{abstract}
Carl Einstein is a not very well known figure within German culture, but his essay Die Fabrikation der Fiktionen remains ignored even among scholars of his work despite containing highly valuable clues to understand the intersection between philosophy and politics that characterizes much of the European thought of the
\end{abstract}


twentieth century. Given this situation, after an initial part where the author's personality and his latest ideas and actions are taken in account, the article makes a thorough review of Die Fabrikation der Fiktionen by doing firstly a comparison of the different interpretations that it has received until now, and continues by carrying out a new reading of its main ideas -the conflict between Realität and Wirklichkeit or the very concept of Fiktion - and an exercise of contrast between the essay and certain works by contemporary thinkers like Siegfried Kracauer and Paul Nizan.

Keywords: avantgarde, conservative revolution, dialectics, fictional apparatus, intellectualism, materialism, reality.

\section{Introducción}

Dice Joseph Roth de Paul Bernheim, uno de los protagonistas de su novela Izquierda y derecha (1929), que en un momento dado «empezó a demoler, una actividad que, en la Alemania de aquellos tiempos, acompañaba a la reconstrucción». ${ }^{1}$ La Alemania en cuestión no era otra sino la del tenso periodo de entreguerras, y aunque por saña o por desidia mucho se había venido abajo en ella, mucho era también lo que requería una embestida adicional, un último golpe de piqueta que diera paso, de una vez por todas, a una regeneración integral. Imbuido como pocos de ese espíritu de creación-destrucción, Carl Einstein (1885-1940) se consagraría enteramente a la tarea desde múltiples perspectivas y mediante iniciativas de toda índole. Al margen de sus escritos sobre arte o sus obras literarias, especial interés tienen en este sentido aquellas obras de pensamiento donde Einstein se debate entre el empirocriticismo de Ernst Mach - «desde una perspectiva teórica, de quien estoy más cerca)-, 2 las doctrinas nietzscheanas y un materialismo que prefigura el de la teoría crítica alemana con el fin declarado de hacer frente a corrientes filosóficas -el neokantismo, la fenomenología o el bergsonismo- que, lejos de paliar el estado de las cosas, estarían a su entender propiciándolo fatídicamente. La progresiva agudización de esos presupuestos determinará la trayectoria vital de Einstein, llevándole de una teoría inducida a partir de la praxis política a una radicalización de dicha teoría que acabará guiando sus acciones finales. En el centro mismo de esa transición entre inducción y deducción epistémica se halla Die Fabrikation der Fiktionen, un texto extraordinariamente anguloso que funciona como ejercicio dialéctico entre modelos de realidad y modelos éticos, y así, entre modos de enfrentar la circunstancia histórica que Europa estaba viviendo. Emplazar Die Fabrikation der

\footnotetext{
${ }^{1}$ Roth, Joseph. Izquierda y derecha. Barcelona: Barataria, 2010 (trad. Sandra Chaparro), p. 119.

2 Einstein, Carl; Kahnweiler, Daniel-Henry. Correspondance 1921-1939 (Liliane Meffre ed.). Marseille: André Dimanche, 1993, p. 144.
} 
Fiktionen en su preciso contexto pasa necesariamente por ubicar a Carl Einstein en el suyo, y por ahí cabe comenzar el análisis de la obra, sobre todo teniendo en cuenta el desconocimiento general acerca del autor.

\section{El intelectual en su laberinto}

Nacido en el seno de una familia judía, inconformista congénito e inclinado desde bien pronto hacia disciplinas muy diversas -al margen de cursar filosofía asistirá a las clases de Hintze, Wölfflin o Simmel en la Friedrich-WilhelmsUniversität de Berlín-, Carl Einstein ronda la veintena cuando se inicia con éxito en la creación literaria gracias a Bebuquin oder Die Dilettanten des Wunders (1907), novela que pasa por ser una de las referencias fundamentales del expresionismo alemán. Quizá sea el sustrato primitivista del movimiento lo que le lleva a abundar en la influencia de la escultura africana en el arte moderno y dar a imprenta el primer estudio sobre la cuestión, Negerplastik (1915), al tiempo que su afán crítico encuentra acomodo en la colaboración directa con George Grosz, John Heartfield o Raoul Hausmann en boletines fuertemente subversivos y en la redacción de un drama satírico, Die schlimme Botschaft, que acarrea su procesamiento judicial por supuestas injurias a la religión católica y, en último término, su exilio en una Francia de la que solo regresará ocasionalmente. Lejos de aquietarse o mantenerse silenciado, los primeros años de desarraigo rinden fruto en la codirección de la mítica revista Documents, numerosas críticas de arte y literatura para publicaciones especializadas, un extenso estudio sobre el pintor Georges Braque y la que sin duda es su obra más ambiciosa, una crónica del arte contemporáneo titulada Die Kunst des 20. Jahrhunderts que verá tres ediciones $(1926,1928,1931)$ ajustadas en tiempo real a los cambios experimentados por la materia durante ese periodo de tiempo.

Sin embargo, contra todo pronóstico y de la noche al día, tras década y media volcado en la mera actividad intelectual y entrado ya en la cincuentena, Einstein decide incorporarse a las milicias anarquistas combatientes en la Guerra Civil Española, en calidad de asesor militar agregado al Grupo Internacional de la Columna Durruti, y con ellas permanecerá hasta el mismísimo final de la contienda. ${ }^{3}$ No es ocioso recordar que, mientras Einstein se encuentra en la vanguardia de la primera confrontación bélica entre democracia y fascismo, sus antiguos camaradas de Documents se dan a la especulación rampante en las sesiones del Collège de Sociologie o al puro esoterismo en los rituales arcaizantes promovidos por Acéphale, aun cuando en uno de sus boletines Georges Bataille se permita procla-

\footnotetext{
3 Cfr. Hartje, Hans. «Carl Einsteins Engagement in Spanien in der Zeit des Bilderkriegs», en Kröger, Marianne; Roland, Hubert (eds). Carl Einstein im Exil. Kunst und Politik in den 1930er Jahren, München: Wilhelm Fink, 2007, pp. 17-28.
} 
mar que «la nostalgia de un mundo perdido reviste numerosas formas, y generalmente es asunto de cobardes [...] de quienes evitan, o no saben que encontrarán, la posibilidad de combatiR. Detrás de la fachada hay, antes que nada [...] ensoñación estética y charlatanería». ${ }^{4}$

Buen cuidado tiene Einstein de contraer el retórico mal, convencido como está de que «hay que saber dónde acaban las palabras», según concluye la carta a su amigo Pablo Picasso del 6 de enero de 1939.5 En la Barcelona sitiada, privado del mínimo vital pero esperanzado como el primer día, Einstein sigue manteniendo que «venceremos a Franco [...] cualquiera que haya estado en el frente lo sabe y lo siente». ${ }^{6}$ Cuando esto escribe el Ejército Popular se está batiendo en retirada hacia la frontera pirenaica y el desconcierto crece en la ciudad a ojos vistas, pero él confía todavía en un acto de justicia moral de dimensiones históricas, de suerte que «si más tarde podremos escribir y pintar libremente será únicamente gracias a la resistencia española». ${ }^{7}$ Fuera de su perspectiva quedan las alianzas de intelectuales antifascistas, los congresos internacionales en defensa de la cultura, las proclamas y manifestaciones de protesta, las intervenciones en los medios de comunicación. «No necesito enrevesadas peroratas ni recetas con ínfulas literarias para ser consciente de mi derecho a la dignidad», ${ }^{8}$ porque «siempre supe que en España estaba defendiendo mi trabajo, la posibilidad de pensar y sentir libremente como individuo», ${ }^{9} \mathrm{y}$ esa necesidad humana sólo podría reivindicarse mediante la intervención directa, «sin discursos ni publicidad», 10 de ahí que resulte muy difícil trazar su peripecia a lo largo de la guerra más allá de su estancia en determinados focos de combate, de la conferencia dictada en éste o aquél ateneo libertario o de ciertos ecos de su estilo rastreables en algún que otro apócrifo cenetista. ${ }^{11}$

Tan desmedido impulso vital alienta su iniciativa sólo en parte, sin embargo. No hay aquí un Jünger aspirando a la ascesis bélica ni un Byron sublimando sus ensoñaciones en la primera causa que le sale al paso, proyectándose en un conflicto para el cual, carente de cualquier formación o experiencia, no está capacitado; cuando

\footnotetext{
4 Bataille, Georges. «Crónica nietzscheana», en AA.VV. Acéphale. Religión. Sociología. Filosofía (1936-1939). Buenos Aires: Caja Negra, 2005 (trad. Margarita Martínez), p. 120.

5 Einstein, Carl; Kahnweiler, Daniel-Henry. Correspondance 1921-1939, op. cit., p. 114.

6 Ibidem, p. 113.

${ }^{7}$ Ibidem, p. 114.

8 Ibidem.

9 Ibidem.

10 Ibidem.

11 Cfr. Kröger, Marianne. «Carl Einstein als politischer Publizist - Die Broschüre von 1937/38 über die NS-Interventionspolitik im Spanienkrieg», en Kröger, Marianne; Roland, Hubert (eds). Carl Einstein im Exil. Kunst und Politik in den 1930er Jahren, op. cit., pp. 29-56, así como Meffre, Liliane. «À propos de quelques documents inconnus concernant Carl Einstein dans le période 1936-1940», en ibidem, pp. 113-121.
} 
Einstein ensalza a los milicianos españoles lo hace «con conocimiento de causa y después de haber pasado por experiencias duras. No crea que somos unos líricos que hacen promesas vanas. Se trata simplemente de la verdad», confiesa a Picasso. ${ }^{12}$ Combatiente en la Primera Guerra Mundial y participante tanto en los consejos revolucionarios que precipitaron la rendición de Alemania como en la revolución espartaquista que le seguiría poco después, Einstein siente la satisfacción de haberse embarcado en una empresa donde ese pasado convulso, tras décadas de inactividad política y reveses de toda especie, encuentra al fin sentido y utilidad. El escritor y periodista holandés Nico Rost recuerda que al reencontrarse con él en Barcelona «parecía, por lo demás, completamente distinto a como era en Berlín: ya no sarcástico, ya no amargado sino entusiasmado y, en consecuencia, rejuvenecido. No lo había conocido así. Sobre su propia vida durante los anteriores difíciles años de la emigración apenas hablaba, y por el contrario una y otra vez comenzaba a hablar del sindicalismo español».13 Tamaña entrega permite entender que se le encomendara radiar el obituario de Buenaventura Durruti coincidiendo con su multitudinario funeral en Barcelona y que en torno a las mismas fechas fuese propuesto para dirigir las operaciones de la columna homónima en el frente de Aragón, ofrecimiento que acabaría rechazando. ${ }^{14}$ De igual forma, su contribución anónima a los Flugschriften o publicaciones volanderas del DAS (Deutsche Anarcho-Syndikalisten, la agrupación barcelonesa de anarquistas alemanes constituida ya en 1933) ${ }^{15}$ y su activa participación en los comités revolucionarios sólo se entienden desde la posición de un compromiso ajeno a cualquier veleidad personalista e instrumental -antagónico al mostrado por Hemingway o Malraux, dicho sea de paso- y fiel tanto a «la sintaxis colectiva» de la Columna Durruti como a la memoria de un líder que -según él- «había suprimido del vocabulario la palabra prehistórica yo». 16

Como tantos otros que aprovecharon la circunstancia bélica para reinventarse a sí mismos y dejar atrás una vida turbia o demediada, Einstein había conseguido borrar casi por completo su identidad: en sus memorias de guerra, Antoine Gimenez

\footnotetext{
12 Einstein, Carl; Kahnweiler, Daniel-Henry. Correspondance 1921-1939, op. cit., pp. 114-115.

13 Rost, Nico. «Mein Freund Carl Einstein», manuscrito conservado en el Carl Einstein Archiv, Akademie der Künste, Berlin, y parcialmente recogido en Penkert, Sibylle. Carl Einstein. Beiträge zu einer Monographie. Göttingen: Vanderhoeck \& Ruprecht, 1969, p. 123.

14 Cfr. Kröger, Marianne. "Carl Einstein und die 'Grupo Internacional' der Kolonne Durruti - ein Beitrag zur Auseinadersetzung Carl Einsteins mit der Realität des Spanischen Bürgerkriegs», en Kiefer, Klaus H. (ed.). Carl-Einstein-Kolloquium 1986. Bern/ Frankfurt a.M./ New York: Peter Lang, 1988, pp. 261-9.

15 Cfr. Nelles, Dieter; Linse, Ulrich; Piotrowski, Harald; García, Carlos. Antifascistas alemanes en Barcelona (1933-1939). El grupo DAS: sus actividades contra la red nazi y en el frente de Aragón. Barcelona: Sintra, 2010 (trad. Harald Piotrowski).

16 Einstein, Carl. «Die Kolonne Durruti», en Einstein, Carl. Werke. Berliner Ausgabe, Band III. 19291940 (Hermann Haarmann, Klaus Siebenhaar eds.). Berlin: Fannei \& Walz, 1996, p. 520.
} 
-nacido Bruno Salvadori- recuerda cómo el Grupo Internacional hacía tabula rasa incorporando en pie de igualdad al marino sueco Nisse Lätt, al ex-coronel fascista Pietro Paolo Vagliasindi y a la filósofa francesa Simone Weil, pasando por una amplia sucesión de buscavidas e idealistas de toda índole habitualmente enrolados bajo seudónimo y sin mención alguna a su pasado civil. ${ }^{17}$ La ya entonces prolongada renuencia a la vida pública y a las tareas que un día le hicieran visible convertían a Einstein en un perfecto anónimo embebido en la acción bélico-revolucionaria, de ahí que el sobresalto del crítico Sebastià Gasch fuese mayúsculo cuando se cruzase con él por las calles de Barcelona. «Nuestra sorpresa estaba justificada. Nunca habríamos dicho, en efecto, que Carl Einstein, de quien no sabíamos nada hacía mucho tiempo, estuviese entre nosotros y luchando por nuestra causa».18 Más allá de la casualidad, el encuentro entre colegas da pie a una jugosa entrevista donde aflora el fuerte desprecio de Einstein hacia determinados intelectuales que «sopor$\tan$ los hechos y no saben crearlos», 19 un desprecio que, ciertamente, impregna al propio interlocutor: no se requiere mucha perspicacia para apreciar que la acusación de seguir «llevando la vida monótona de antes», y de caer «en un conformismo teórico sin arriesgar la piel» 20 incluye a un Gasch que en plena contienda permanece fiel a sus ocupaciones habituales - valga la propia entrevista como prueba- y han desatendido la que sería su auténtica responsabilidad: pasar a la acción directa en defensa de la legitimidad republicana y de la libertad en general.

\section{Genealogía del desencanto}

Si bien las declaraciones de Carl Einstein marcan un punto de inflexión en su trayectoria, y un punto de no retorno, de hecho, lo cierto es que meses atrás había dejado a un lado el que debía ser su particular ajuste de cuentas sobre la cuestión, Die Fabrikation der Fiktionen (La fabricación de ficciones), extensa diatriba contra la intelectualidad del momento que no vería la luz sino mucho después de su muerte y aún así en condiciones ciertamente perfectibles. ${ }^{21}$ Escrito anómalo en el

17 Cfr. Gimenez, Antoine. Del amor, la guerra y la revolución. Recuerdos de la guerra de España del 19 de julio de 1936 al 9 de febrero de 1939. Logroño: Pepitas de calabaza, 2009 (trads. Francisco Madrid, Carlos García, Los Gimenólogos).

18 Gasch, Sebastià. «Unes declaracions sensacionals de Carl Einstein. Miró i Dalí i l'art revolucionari. El rol dels intel.lectuals», en Meridià. Setmanari de literatura, art i política. Tribuna del Front Intel.lectual Antifeixista. Barcelona, 6 de mayo de 1938, p. 4 [desplegable facsimilar incluido en Einstein, Carl. La Columna Durruti y otros artículos y entrevistas de la Guerra Civil Española (Uwe Fleckner ed.). Barcelona: Mudito \& Co, 2006 (trads. Arnim Schulz, Juan José Lahuerta)].

19 Ibidem.

20 Ibidem.

21 Einstein, Carl. Die Fabrikation der Fiktionen. Reimbeck: Rowohlt, 1973. Editada por Sybille Penkert, investigadora pionera en la recuperación de la figura y la obra de Carl Einstein, se ha achacado a su versión de Die Fabrikation der Fiktionen -única disponible hasta hoy- el hecho de carecer 
conjunto de una producción caracterizada de suyo por la anomalía, Die Fabrikation der Fiktionen resulta de una larga labor que iría fructificando en sucesivas copias plagadas de añadidos, tachaduras y enmiendas pero cuya continuación apenas puede conjeturarse al no constar esquema de desarrollo alguno. ${ }^{22}$ De hecho, su extensión tanto en la forma como en el tiempo llevan a pensar que el texto cumpliría menos como entidad cerrada que como una empresa de dimensiones apenas preestablecidas. «Judío sin dios ni conocimiento de nuestro pasado, germanohablante, pero resuelto a no dejar que, por indolencia y cansancio, la lengua alemana se vaya a pique [...] ahora conversaré brevemente conmigo mismo día tras día»,23 admite al poco de instalarse en París, luego bien puede decirse que esta perorata del apestado cumple como puesta por escrito de sus cuitas y como asunción de su doble extraterritorialidad, la física y la intelectual. «Porque desde hace mucho tiempo estoy incomunicado de personas y libros de mi misma lengua» y «en la poesía francesa nunca me sentiré como en casa»,24 Einstein emplea su lenguaje como una materia bruta no coercida por mesura o rigor de ningún tipo, por convención moral o formal alguna, y es así como esta invectiva, que se ha querido comparar en tono a los escritos finales de Nietzsche y en determinación a las proclamas antiburguesas de Brecht, 25 mantiene íntegra su energía página tras página y versión tras versión. Como escribiera otro intelectual no menos crítico con su gremio y con la realidad que le tocara en suerte, George Orwell, «para escribir en un lenguaje simple y vigoroso es preciso pensar de forma intrépida, y en cuanto se empieza a pensar de forma intrépida ya no se puede volver a ser políticamente ortodoxo». ${ }^{26}$

Aplicable a Einstein es el juicio que emite Canetti sobre Karl Kraus, cuando afirma que en sus ensayos «todo ocurre con la misma intensidad, todo es absorbido

de aparato crítico y de haber sido confeccionada mediante criterios científicos discutibles, circunstancia que, unida al carácter problemático del texto, explicaría en parte la escasa consideración mostrada hacia él no solo por especialistas en el pensamiento alemán de entreguerras sino también por expertos en la obra einsteiniana.

22 Si bien la fecha de la última corrección (1936) aparece en la cuarta de las copias conservadas en el Carl Einstein Archiv (la D/E o M Iff, matriz de la edición de Penkert) y, aunque no se tiene certeza de cuándo inició Einstein la tarea, en su correspondencia se hace mención al proyecto ya desde mediados de 1932, y todo apunta a que no pudo haber sido emprendido antes de finales de 1931. El hecho de que junto al título de la primera copia mecanografiada (la versión A o M 49ff) aparezca anotada de su puño y letra su dirección postal en aquellos momentos ( 3 Avenue Champaubert, Paris XV) vendría a corroborar esta hipótesis -siempre y cuando dicha anotación, obviamente, fuese contemporánea al texto.

23 Anotación del 18 de febrero de 1933, conservada en el Carl Einstein Archiv y recogida en Penkert, Sibylle. Carl Einstein. Beiträge zu einer Monographie, op. cit., p. 120.

24 Ibidem.

25 Heißenbuttel, Helmut. «Zusätze zur 'Fabrikation der Fiktionen'», en Einstein, Carl. Die Fabrikation der Fiktionen, op. cit., p. 8.

26 Orwell, George. The Collected Essays, Journalism and Letters of George Orwell, vol. IV. New York: Harcourt, Brace and World, 1968, p. 66. 
por el mismo lenguaje en igualdad de importancia, sentimos cómo el ataque se vuelve siempre sobre sí mismo»,27 y aunque el tono desabrido, unido a un desdén por el estilo entendido como rasgo estilístico en sí mismo, bastarían para hacer acreedor a un texto como Die Fabrikation der Fiktionen del calificativo de panfleto, bueno es recordar que es en los tres estudios que acompañan a la edición póstuma de 1973 donde esa categorización adquiere oficialmente carta de naturaleza. Ya en el prefacio Helmut Heißenbüttel incide en el hecho de que las formulaciones brutalmente apodícticas, así como «el continuo recomienzo de los planteamientos categóricos, las recapitulaciones, el avance de la argumentación mediante bucles, la simplificación de los planteamientos en polémicas siempre nuevas, ocupan el lugar del desarrollo lógico-teórico tradicional». ${ }^{28} \mathrm{~A}$ la luz de esta lectura sería el propio armazón expositivo lo que situaría la obra en los dominios de lo panfletario, y ello en virtud de una acusada subversión de las convenciones formales que Sibylle Penkert interpreta, por su parte, en clave "artística", al vincularla no tanto a un modo locutivo cuanto a la querencia expresionista del autor -una interpretación especialmente razonable si tomamos en cuenta que en esos años Einstein se encontraba trabajando simultáneamente en una secuela de Bebuquin que tampoco vería finalmente la luz. ${ }^{29}$ Die Fabrikation der Fiktionen actuaría, según esto, como una extensión de su obra literaria donde la intención alegórica o el despliegue narrativo hubiesen sido sustituidos por una retahíla de reflexiones que mantendrían el tono existencial característico de Bebuquin mediante recursos de nuevo cuño y conformarían así un escrito a caballo entre lo vanguardista y lo filosófico. Katrin Sello, por último, sustentará la calificación de panfleto en el carácter imprecatorio e instrumental de la obra, perfil reforzado por la evidente toma de posición y por el salvaje ataque contra las prerrogativas conservadoras que desde dicha posición se lleva a efecto. Es sin duda esta agresividad el mejor aval para adscribir el texto a la tradición panfletaria, aunque hacerlo conlleve admitir tácitamente que responde a una estrategia prefijada, y ya Hubert Roland deja bien claro que «una interpretación de Die Fabrikation der Fiktionen como manifiesto político no se deja entender, sobre todo porque en el fondo no se bosqueja en el texto ningún tipo de manifiesto polí-

\footnotetext{
27 Canetti, Elias. La conciencia de las palabras. México D.F.: Fondo de Cultura Económica, 1994 (trad. Juan José del Solar), p. 321.

${ }^{28}$ Heißenbuttel, Helmut. «Zusätze zur 'Fabrikation der Fiktionen'», en Einstein, Carl. Die Fabrikation der Fiktionen, op. cit., p. 8.

${ }^{29} \mathrm{El}$ manuscrito, que consta en modo fragmentario bajo la signatura BEB II en el Carl Einstein Archiv de la Akademie der Künste de Berlín, ha sido profusamente analizado en: Kröger, Marianne. Das 'Individuum als Fossil' - Carl Einsteins Romanfragmente 'BEB II'; das Verhältnis von Autobiographie, Kunst und Politik in einem Avantgardeprojekt zwischen Weimarer Republik und Exil. Remscheid: Gardez, 2007. Como introducción general al texto, cfr. Kiefer, Klaus H. «'BEB II'. Ein Phantombild», en AA.VV. Text + Kritik, $n^{\circ} 95$ ( $\mathrm{n}^{\circ}$ especial dedicado a Carl Einstein), München, julio 1987, pp. 44-66.
} 
tico», ${ }^{30}$ cuando menos de manera explícita y razonada. De hecho, las cuatrocientas ochenta páginas de la última copia apenas permiten pensar que la obra hubiese funcionado como homilía destinada a la agitación de conciencias, por mucho que las frases cortas, el tono admonitorio y el constante martilleo de un puñado de argumentos puedan denotar una finalidad didáctica basada en el puro aleccionamiento, y por mucho que tales rasgos hayan llevado a especialistas como Liliane Meffre a conceptuar la obra como «ensayo de prosa popular». 31

A contracorriente de lecturas que traslucen cierto temor a los zarpazos del texto -Penkert no duda en tildarlo de «monstruoso panfleto»-,32 Wolfhart Henckmann subraya las cualidades funcionales de un Propagandaschrift (escrito propagandístico) cuyo primer destinatario sería la conciencia común y cuya energía «podría entenderse como algo constructivo, como una crítica transitiva a los asuntos colectivos» ${ }^{33}$ que, en línea con cierta heurística de vanguardia, propone destruyendo. Este énfasis en el carácter productivo del documento permite inscribirlo con mayor naturalidad en el quehacer einsteiniano, al abundar en la relación entre intención fuerte y forma extrema que el autor ejercitarse en sus escarceos dadaístas y al emparentarlo con el principio activo-reactivo consustancial a dicho movimiento. De este modo, si considerar Die Pleite o Der blutige Ernst -las publicaciones que editara con Georges Grosz- como simples libelos significaría pasar por alto su estructura formal -la estudiada urdimbre de lo tipográfico y lo caricaturesco, por ejemplo- y desvirtuar por completo su ambición crítica -bien alejada del sesgo lúdico-experimental de la matriz Dada de Zürich o de la entropía estetizante de sus epígonos parisinos-, así tomar Die Fabrikation der Fiktionen como una rocambolesca sucesión de agravios llevaría aparejado un fatal desfiguramiento de su carácter real. No en vano, Erich Kleinschmidt arguye que «a fin de cuentas la ilegibilidad de Fabrikation der Fiktionen no debería ser entendida como resultado de una desordenada disposición articulada mediante repeticiones», sino que «se legitima a sí misma en el contexto de una genuina praxis textual de lo moderno» al sustentarse más «en el movimiento de presentación que en la fijación».34 En la práctica, esta

30 Roland, Hubert. «Es muß wieder eine gemeinschaftliche Wirklichkeit erkämpft werden, weiter nichts'. Ungeklärte Ambivalenzen bei Carl Einstein», en Kröger, Marianne; Roland, Hubert (eds). Carl Einstein im Exil. Kunst und Politik in den 1930er Jahren, op. cit., p. 164.

31 Meffre, Liliane. Carl Einstein et la problématique des avant-gardes dans les arts plastiques. Bern/ Frankfurt a.M./ New York: Peter Lang, 1989, p. 132.

32 Penkert, Sibylle. «Explication-Edition-Interpretation», en Einstein, Carl. Die Fabrikation der Fiktionen, op. cit., p. 334. En esta línea se sitúa la propia Meffre cuando se refiere a él como «verdadero juego de masacre» (Meffre, Liliane. Carl Einstein et la problématique des avant-gardes dans les arts plastiques, op. cit., p. 119).

33 Henckmann, Wolfhart. «Zur Argumentationsweise in Einsteins Fabrikation der Fiktionen», en Kiefer, Klaus H. (ed.). Carl-Einstein-Kolloquium 1994. Bern/ Frankfurt a.M./ New York: Peter Lang, 1996, p. 152.

34 Kleinschmidt, Erich. «Die Dekonstruktion der Moderne in Carl Einsteins Die Fabrikation der 
dinámica de mostración se consuma gracias a un discurso metódicamente ametódico-consustancial al género ensayístico, en opinión de Adorno- mediante el cual los distintos núcleos argumentales se ven forzados a concurrir y cohabitar en el texto, circunstancia que genera toda suerte de alianzas y fricciones y en consecuencia, como en los fotomontajes de su contemporánea Hannah Höch, descargas de insospechado sentido. El propio Einstein reconoce hacia 1930 en una carta a Ewald Wasmuth no poder sustraerse a esta metodología, al admitir que "soy consciente de ser cada vez menos sistemático, tengo una aversión hacia las síntesis [...] veo siempre en lo sistemático el límite donde surge un problema que no puede ser superado por el propio sistema», ${ }^{35}$ luego esta red tejida por paradojas, quiasmos y demás escaramuzas sintácticas y semánticas no sería sino el reflejo de un pensamiento que va configurándose sobre la marcha, de un discurso desovillado en el curso de su propia enunciación, y su carácter angular el resultado de una reflexión que exige una forma a su justa medida, y ninguna otra. 36

Así las cosas, que el cariz insidioso y la peculiaridad formal de Fabrikation der Fiktionen hayan llevado a más de uno a calificarla de mero ajuste de cuentas no es distinto a negar que el trazo astillado de Max Beckmann o la acritud de Otto Dix denotan una crítica de gran envergadura: en ellos, como en muchos de sus contemporáneos, la ruptura de la unidad discursiva mediante el multiperspectivismo, la hipérbole y la deformación grotesca remiten a la esquizofrenia de una sociedad en crisis aguda, a la descomposición de la mismísima Modernidad. Sabido es que la puesta entre paréntesis del proyecto moderno actúa como una constante en la intelectualidad centroeuropea del momento, de Joseph Roth a Erwin Piscator y de Kurt Weill a Hermann Broch, y si ésta ha llegado hoy a ser considerada la canónica generación moderna se debe justamente a que situó en la labor autocrítica uno de los fundamentos de lo moderno, en el convencimiento de que la constante revisión de lo logrado mantenía a raya el riesgo de colapso mediante la pertinente detección de sus síntomas y a la vez forzaba el desbordamiento de los propios márgenes de acción. Die Fabrikation der Fiktionen se acoge con todas sus consecuencias a estos principios porque actúa como puesta en evidencia de cuantos artificios, disfuncio-

Fiktionen», en Kröger, Marianne; Roland, Hubert (eds). Carl Einstein im Exil. Kunst und Politik in den 1930er Jahren, op. cit., p. 145.

35 Cit. en Franke-Gremmelspacher, Ines. 'Notwendigkeit der Kunst?'. Zu den späten Schriften Carl Einsteins. Stuttgart: Hans-Dieter Heinz, 1989, p. 87. En su correspondencia con Kahnweiler, Einstein justifica su aversión hacia lo sistemático en términos de una empatía y una responsabilidad hacia su propio tiempo: «Hablo de manera poco sistemática. Simplemente porque no puedo permitirme el lujo de dar vueltas a estas cosas y ver al mismo tiempo, en medio de todo eso, cómo prosigue la catástrofe diaria». Einstein, Carl; Kahnweiler, Daniel-Henry. Correspondance 1921-1939, op. cit., p. 142.

36 Nótese que, en el contexto de este estudio, la tarea analítica pasa en buena medida por un "desmontaje" y posterior "organización" del documento - los saltos entre las páginas de procedencia de las citas son prueba de ello- en aras de una articulación argumental que lleva inevitablemente aparejada una desvirtuación de su plasticidad original. 
nes e inconsistencias pueblan la época en que está redactada, circunstancia que lleva a Kleinschmidt a afirmar que «su radicalidad deriva de la escenificación de un borrado y sobreescritura del proyecto moderno», 37 de suerte que «la estructura subyacente al texto se aclara solamente cuando se apercibe uno de que el discurso del autor no sólo negocia con una historia crítica de la estética moderna y su consiguiente subjetivismo, sino que asume también la irrepresentabilidad de la fractura de esta modernidad, con sus sombras y deformaciones». 38

Este ensañamiento con aquello que motiva el texto y a la vez determina su apariencia sólo puede entenderse en términos de una huida hacia adelante que condujese a una feroz autodestrucción, habida cuenta de que las prédicas de Einstein se dirigen a su pasado inmediato y al estatus que en ese mismo momento, pese al amargo exilio, sigue ocupando en la sociedad. Por no recurrir a los análisis de un Kraus, un Mann o un Musil, tal vez un breve ensayo próximo en el tiempo a Die Fabrikation der Fiktionen pueda ayudar a situar el contexto y la apuesta einsteiniana en sus justos términos. Publicado en su día en el Frankfurter Zeitung-verdadero boletín oficial del estado intelectual alemán-, Die Wartenden ("Los que esperan") se presenta como un retrato de grupo en el que Siegfried Kracauer examina mediante trazos genéricos, apenas vinculados a referencias específicas, las principales actitudes de la intelectualidad de la época. Inscrito en la nutrida literatura que negociaba con el desmoronamiento de los antiguos sistemas de valores, Die Wartenden es una lacónica cartografía del desamparo, una diagnosis que, en medio del «sufrimiento metafísico de la falta de un sentido superior en el mundo», 39 en expresión del autor, intenta abordar más «la situación espiritual en la que se encuentran las personas aquí consideradas que el despliegue de los problemas históricos $\gg 40$ conducentes a dicha situación. Desorientados, prisioneros de un relativismo atroz, la comunidad social ya no es para estos intelectuales una entidad preexistente sino «un mero concepto», 41 una abstracción que les mueve a concebir formas de unión supraindividual basadas en nuevos ideales aun a sabiendas de que quizá ni ellos mismos puedan formar parte de ellas. Su aislamiento les concede una posición privilegiada al mantenerlos en estado estacionario con respecto a las circunstancias: «igualmente cerca, pues se sumergen con facilidad en cada especialidad, debido a que ya ninguna fe atrapa su espíritu y le impide de tal modo incorporarse a un fenómeno cualquiera del modo que le plazca», pero asimismo «igualmente lejos, pues

\footnotetext{
37 Kleinschmidt, Erich. «Die Dekonstruktion der Moderne in Carl Einsteins Die Fabrikation der Fiktionen», op. cit., p. 134.

38 Ibidem, p. 139.

39 Kracauer, Siegfried. «Los que esperan», en Kracauer, Siegfried. La fotografía y otros ensayos. El ornamento de la masa I. Barcelona: Gedisa, 2008 (trad. Laura S. Carugati), p. 111.

40 Ibidem, p. 112.

41 Ibidem, p. 113.
} 
nunca consideran un conocimiento como el último, nunca se han introducido tan profundamente en una esencialidad como para poder ingresar en su profundidad permanentemente y al mismo tiempo no poder salir más de ella».42

A la luz de este posicionamiento liminar, Kracauer establece la existencia de intelectuales que tomarían ese «vaciamiento espiritual del espacio que nos circunda» ${ }^{43}$ como un ideal a la medida exacta de sus ambiciones, de otros que se habrían rebelado contra él impulsados por un afán fuertemente nostálgico, y de un tercer grupo, por último, cuya opción pasaría por permanecer a la expectativa, en un estado de autoinducida latencia. «El primer modo -indica Kracauer- es el del escéptico por principio, que quizá ha encontrado su mayor representación en Weber. Se trata del hombre que comprende claramente la tremenda seriedad de la situación, pero que al mismo tiempo está convencido de que él y sus iguales no pueden liberarse de ella», ${ }^{44}$ circunstancia que en último término le ha llevado a una suspensión cautelar de su conciencia crítica. En el segundo modo de comportamiento, por el contrario, «la fe es más una voluntad de creer que una permanencia en la creencia», más una «casilla protectora» 45 que una firme convicción. Sus practicantes recibirían el calificativo de hombres-cortocircuito porque, «a partir del reconocimiento de la necesidad de la fe y con una nostalgia completamente impaciente, entran en un ámbito de la fe en el cual-debido a que les faltan las condiciones previas extensivas para su verdadera conquista- sólo se pueden mantener artificialmente y en virtud del autoengaño voluntario».46 Suele darse en estos intelectuales cierta inclinación a un gregarismo sectario -vienen aquí a la mente los acólitos de Stefan George o la referida comunidad de Acéphale - al que nunca sucumbirían quienes, por último, convierten la incertidumbre en pura expectativa, en un solitario y «dubitativo estar abierto» 47 que, lejos de flirtear con la indolencia, «consiste en una actividad tensa y en un prepararse activo» 48 plenamente acorde con aquello que Raymond Aron, definiendo su propia postura, denominase comprometida observación.

Ahora bien, ¿un prepararse activo con qué fin y a la espera de qué, se pregunta uno? ¿A un incremento del déficit de la razón, a una mayor agudización, si cabe, de las tensiones políticas? ¿Quizá a algún hecho que aumente de forma irreversible la temperatura social? De ser así, el propio Kracauer, que escaparía de Berlín justo un día después del incendio del Reichstag, y no uno antes, sería el mejor ejemplo de hasta qué punto semejante postura habría servido para, si no propiciar, sí al menos dejar expedito el camino que acabaría conduciendo a la catástrofe. Einstein

\footnotetext{
42 Ibidem, pp. 113-4

43 Ibidem, p. 111.

44 Ibidem, p. 119.

45 Ibidem, p. 120.

46 Ibidem, p. 121.

47 Ibidem, p. 122.

48 Ibidem, p. 123.
} 
no puede estar más lejos de esa actitud, y es indudable que alude a cuantos se sentaron a verlas venir y sin embargo dieron prueba de una fatídica miopía cuando deja caer que «los intelectuales estaban muy orgullosos de su actitud negativa y de su estéril soledad» ${ }^{49}$ y en su incuria llevaron implícita la penitencia. Una lasitud no ceñida en exclusiva al ámbito alemán, por lo demás, pues «durante largo tiempo -remacha-, los intelectuales de la Europa occidental habían observado la existencia de forma teórica y no estaban formados ni determinados para ningún tipo de acción», 50 circunstancia que acabaría teniendo funestas consecuencias en la humanidad al completo. Con todo, no es tanto la denuncia de esa fatal pasividad lo que alienta Die Fabrikation der Fiktionen cuanto la puesta en cuestión del hábito que unos y otros compartían por definición, de ese afán autolegitimador que les impulsaría a generar ideas y productos culturales por puro hábito y a despecho de la necesidad colectiva. Concluía Kracauer su ensayo afirmando que «para los hombres aquí mencionados se trata del intento de transferir el punto central del yo teórico al yo humano entero y salir del mundo irreal atomizado de poderes disformes y de las formas desprovistas de sentido para entrar en el mundo de la realidad y de las esferas abarcadas por él», 51 sin reparar en que exactamente ahí residía el más grave problema, la mayor tara de esa comunidad reconcentrada: esa realidad elaborada a su medida apenas guardaba relación con la expuesta a la luz del día, con el quehacer del individuo común, con lo factual.

\section{Realidades en conflicto}

En un ensayo contemporáneo al de Kracauer que daría pie a una sustanciosa polémica, Julien Benda cifra la traición de los intelectuales en su progresivo y fatídico desvío no ya hacia posiciones políticas contrarias al proyecto ilustrado sino hacia el ejercicio político en sí.52 Partidario de una nítida separación de funciones, Benda considera que el intelectual ha de actuar como una referencia meramente ética en medio del vendaval de los avatares históricos, de suerte que, como dijera Rolf Dahrendorf, «su profesión sería como un acompañamiento crítico de lo que va aconteciendo» 53 que en modo alguno conllevaría una participación directa, justamente porque el mantenimiento de esa distancia le permitiría pulsar y evaluar el

\footnotetext{
49 Einstein, Carl. Die Fabrikation der Fiktionen, op. cit., p. 322.

50 Ibidem, p. 302.

51 Kracauer, Siegfried. «Los que esperan», op. cit., p. 124.

52 Cfr. Benda, Julien. La traición de los intelectuales. Barcelona: Galaxia Gutenberg, 2008 (trad. Rodolfo Berraquero). Su propia visión de la controversia suscitada por el libro puede encontrarse en Benda, Julien. Memorias de un intelectual. Madrid: Espasa-Calpe, 2005 (trad. Xavier Pericay), pp. 259-269.

53 Dahrendorf, Ralf. La libertad a prueba. Los intelectuales frente a la tentación totalitaria. Madrid: Trotta, 2009 (trad. Pedro Madrigal), p. 23.
} 
presente y a la vez mantenerse a resguardo de las disputas consustanciales a la Realpolitik. Quizá no exista caracterización menos aplicable al propio Einstein, a un "pensador en ejercicio" que concibe su actividad en términos de una intervención directa y constante en lo real. De hecho, argumentar que la deriva de la intelectualidad hacia una autonomía estamental constituye una contradictio in terminis únicamente requiere recordar cómo el soporte de sus acciones -publicaciones, conferencias y demás- comporta de suyo una dimensión abierta, comunitaria, social, de ahí que Einstein entienda «la supremacía de la contemplación y del tipo expectativo» 54 como la apoteosis del cinismo, y de ahí también la calidad de un envite que viene a instituirse a sí mismo, por propósito, articulación y textura, como alternativa a la inoperante tibieza de sus pares.

«Los intelectuales se neutralizaron a sí mismos: eran apolíticos y se comportaban como espectadores distantes» ${ }^{55}$ aglutinados en torno a una «empresa aristocrática» ${ }^{56}$ que viene a situarse en el punto de mira de Die Fabrikation der Fiktionen. Aunque el término intelectual se incorpora al alemán como préstamo lingüístico a raíz del caso Dreyfus, lo cierto es que la nominalización que antaño había experimentado el adjetivo da cuenta de un sentido bien distinto, de un uso que está, de hecho, en la base de la degradación denunciada por Einstein. Basta con atender al concepto de intuición intelectual urdido por Kant para definir una facultad que trascendería la nuda percepción del mundo para entender el uso del término que a finales del siglo XVIII hace Wieland en su Conversación entre el actor y el lector, donde se atribuye a aquellos individuos poseedores de dicha facultad intelectual (das Intellektuelle) una posición excepcional dentro de la sociedad y una tácita autoridad que no dudarán en ejercer. ${ }^{57}$ La historia del siglo XIX y la del primer tercio del XX abunda en ejemplos de una confianza malversada que lleva a Einstein a afirmar taxativamente que «los intelectuales conquistaron el monopolio del sistema de valores» 58 , «se arrogaron el monopolio de la verdad» ${ }^{59}$ y, en consecuencia, «el de la libertad». $60 \mathrm{Al}$ cedérseles toda competencia epistémica en virtud de su supuesta excelencia apenas tardaron en atribuirse la gestión omnímoda del funcionamiento

\footnotetext{
54 Einstein, Carl. Die Fabrikation der Fiktionen, op. cit., p. 302.

55 Ibidem, p. 130.

56 Ibidem, p. 114. Bueno es recordar que en la Francia donde emite Einstein este juicio los intelectuales se cobijan bajo la bandera de la Confédération des Travailleurs Intellectuels o, en su defecto - esto es, si se identifican a sí mismos como esprits réputés ingroupables-, al amparo de los muy elocuentemente autodenominados Compagnons de l'Intelligence.

57 Cfr. Phelan, Anthony. «El tema del intelectual: discusión y acción», en Phelan, Anthony. El dilema de Weimar. Los intelectuales en la república de Weimar. Valencia: Alfons el Magnànim, 1990 (trad. Josep $\mathrm{M}^{\mathrm{a}}$ Domingo), pp. 21-66.

58 Einstein, Carl. Die Fabrikation der Fiktionen, op. cit., p. 19.

59 Ibidem, p. 79.

60 Ibidem, p. 126.
} 
social, lo cual significaba que en términos ejecutivos la cultura reemplazaba a la política y condicionaba por sí sola la praxis social, sepultándola bajo un abrumador despliegue de elementos autónomos, bajo «un mercado de ilusiones e idealizaciones» ${ }^{61}$ que para Einstein vendría a certificar «la vieja huida de los intelectuales de la realidad». 62

Como sucedía con el mencionado ensayo de Kracauer, el propio título Die Fabrikation der Fiktionen contiene la clave de lo que el autor se trae entre manos, siendo que el término ficción no está aquí vinculado a la estructura característica de la novela y demás artes narrativas sino, in extenso, a un utillaje retórico que actúa más como parapeto para protegerse de las circunstancias que como soporte para desbaratarlas o trascenderlas, a un mecanismo que «apenas amplía la existencia sino que ignora u obstaculiza los distintos procesos sociales mediante la arbitrariedad aislada», 63 toda vez que «la ficción no es ninguna creación autónoma sino una variante de lo real en su forma regresiva».64 En buena ley, podría decirse que Einstein pone en evidencia la versión contemporánea y depauperada de aquella constante antropológica que, por aquellos años, un Ernst Cassirer bien alejado de sus presupuestos epistemológicos bautizase con el nombre de forma simbólica. Defiende Cassirer que, frente a la actividad movediza de la conciencia -mayor, si cabe, en el mundo moderno-, el ser humano acostumbra a establecer elementos de fijación que mantengan una cierta significación invariable, dado que «la fluctuante impresión sólo alcanza para nosotros forma y permanencia cuando la afrontamos constitutivamente en cualquiera de las dimensiones de la simbolización». 65 En respuesta a esta necesidad, las formas simbólicas permitirían una condensación de lo cognoscible disperso bajo estructuras estables que se constituirían en verdaderas creadoras de sentido e incluso, se diría, en órganos, por cuanto «sólo merced a ellas llega lo real a ser objeto de la visión intelectual, y así visible sin más».66 Al estar cada forma simbólica determinada por cierta sujeción a la realidad y por cierta independencia con respecto a ella, es evidente que se corre el riesgo de generar un desequilibrio que repercuta en la experiencia y en la conciencia de lo real, y es justamente a denunciar el peligroso hiato alcanzado en la Modernidad que se encomienda la acción crítica de Einstein, tras haber llegado un punto en el cual «los intelec-

${ }^{61}$ Ibidem, p. 14.

62 Ibidem, p. 20. De hecho, la fatal renuncia a la política en favor de la cultura es el principal argumento del que se sirve Wolf Lepenies para criticar el errático rumbo de la tradición intelectual europea y, muy especialmente, de la alemana. Cfr. Lepenies, Wolf. La seducción de la cultura en la historia alemana. Madrid: Akal, 2008 (trad. Jaime Blasco), pp. 17-36.

63 Ibidem, p. 132.

64 Ibidem, p. 126.

65 Cassirer, Ernst. Filosofía de las formas simbólicas (vol. I: El lenguaje). Madrid: Fondo de Cultura Económica, 1998 (trad. Armando Morones), p. 52.

66 Ibidem, p. 84. 
tuales creyeron poder reemplazar a discreción cualquier hecho por un millar de símbolos» $67 \mathrm{y}$, ensoberbecidos, «instituyeron en lugar de la dialéctica concreta un juego de abstractas metáforas [...] en lugar de los conflictos actuales, sistemas uniformes $\sin$ dificultades». 68

Se diría que, encantados de asistir al weberiano desencantamiento del mundo moderno, hubo quienes no perdieron ni un segundo en restituir por su cuenta y riesgo la fantasía perdida, y Die Fabrikation der Fiktionen viene a proponerse justamente como un movimiento de contraataque a esta situación, como un ejercicio de «dialéctica de lo real».69 El propio subtítulo de la obra, Eine Verteidigung des Wirklichen (Una defensa de lo real), basta para ilustrar esa intención a poco que reparemos en el hecho de que, aun refiriendo por lo común una misma entidad (uno y otro término pueden verterse al castellano como "realidad"), Einstein adscribe casi invariablemente la noción de Wirklichkeit al campo semántico del proletariadomasa y la de Realität al de la intelectualidad, de modo que su posición dentro del contencioso queda definida desde el mismísimo encabezamiento. ${ }^{70}$ Pese a las restricciones que impone la escasa sistematización del texto, dicho enfoque presenta la originalidad de sustituir el clásico análisis político o económico de la lucha de clases - «el conflicto entre las formulaciones de una minoría y las fuerzas colectivas de la Historia», en palabras del propio Einstein-71 por una confrontación de sus respectivas Weltanschauungen, lo que en la práctica se traduce en una fricción entre la experiencia mundana y su recreación facultativa, entre un modo directo y un modo interpuesto de acceso a la realidad. Quedará decepcionado, sin embargo, quien busque aquí un pormenorizado desglose de ambas magnitudes: equiparable en esto a la propia circunstancia vital del autor, la Wirklichkeit cumple en el discurso como una realidad exiliada cuyo eventual regreso pasa por derrocar el trasunto de realidad que la forzó al destierro, de modo que el texto se concibe como una maniobra envolvente contra la Realität en la esperanza de que, una vez vencida, la Wirklichkeit emerja a la manera de una verdad objetiva, presentando entretanto el paradójico aspecto de una sólida abstracción. «El texto de Einstein -indica a este respecto Kleinschmidt- justifica su propia existencia mediante una epistemología negativa que funciona al mismo tiempo como superación productiva», ${ }^{72}$ como un ejercicio

67 Einstein, Carl. Die Fabrikation der Fiktionen, op. cit., p. 315.

68 Ibidem, p. 209.

69 Ibidem, p. 300.

${ }^{70}$ Heidemarie Oehm subraya este posicionamiento para sostener la tesis de una revaloración materialista (materialistische Umwertung) experimentada por el discurso einsteiniano, tesis que ha sido sistemáticamente puesta en cuestión por autores que, por el contrario, defienden una continuidad -acaso radicalizada en este periodo- de los presupuestos del autor. Cfr. Oehm, Heidemarie. Die Kunsttheorie Carl Einsteins. München: Wilhelm Fink, 1976, pp. 159-64.

71 Einstein, Carl. Die Fabrikation der Fiktionen, op. cit., p. 283.

72 Roland, Hubert. «Die Dekonstruktion der Moderne in Carl Einsteins 'Die Fabrikation der Fiktionen'», op. cit., p. 144. 
de abolición y sustitución de -así Einstein- esa «realidad (Realität) de los grupos dominantes que excluía el máximo de vida y realidad (Wirklichkeit)». ${ }^{73}$ Con esta metodología, en fin, no se pretendería sino desmontar el programa que «los de arriba» 74 aplican sistemáticamente desde que ostentan el poder, este es, el de la sistemática sustitución de la vida ordinaria por un estupefaciente carrusel de ilusiones, por un artefacto análogo a aquello que Marx denominase fantasmagoría y que por esas fechas o décadas más tarde, grosso modo y con todas las salvedades necesarias, otros designarán con expresiones como ornamento de masas, sociedad del espectáculo o cultura del simulacro.

Habida cuenta de la dificultad de la empresa, Wirklichkeit y Realität no se confrontarán por sí mismas sino a través de sus correspondientes pantallas o poderhabientes, estas son, Wirklichkeitsbilder (imágenes de realidad) y Fiktionen (ficciones), permitiendo a Einstein un desarrollo de corte relacional basado en un juego de oposiciones más genéricas que sustanciales. Así, serán las divergencias entre uno y otro mecanismo de proyección-mediación las que en la práctica saquen a la luz las existentes entre ambos modos de realidad, al tiempo que evidencien un desigual contenido de valor y verdad: en tanto las Wirklichkeitsbilder son indicios unidos con aquello que refieren por vínculos de necesidad, las Fiktionen devienen meras convenciones sin mayor vínculo efectivo, «una masa de fantasmas privados» 75 que no precisan de lo real sensible para sostenerse en pie. La extensa familia semántica que uno y otro campo despliegan a lo largo de la obra, enhebrando conceptos como los referidos Fantasma y Symbol (fantasma, símbolo) con otros como Metapher, Traum, Vision, Aberglaube, Einbildung, Wahn, Hypothese o Weltbild (metáfora, sueño, visión, superstición, quimera, ilusión, hipótesis e imagen del mundo, respectivamente), es propia de aquellas modalidades de la imagen -las imágenes perceptivas, mentales y lingüísticas- cuyo rasgo común es la intangibilidad, luego basta que este etéreo arsenal se contraponga al materialismo incontestable de los Tatsache, Geschehnis y Ereignis (hecho, acontecimiento, suceso) para que la calidad del conflicto se manifieste con la máxima elocuencia. En estas circunstancias, mientras Einstein denuncia que «ahora disponían los intelectuales de objetos ideales y los hechos objetivos quedaban en segundo lugar», ${ }^{76}$ otros, como Paul Valéry -que no duda en adherirse a los antidreyfusards y llegado el momento permanecerá impávido ante la invasión de su país-, se ufanan precisamente de que «la tarea de los intelectuales consiste en mezclar los signos, los nombres o los símbolos de todas las cosas sin el contrapeso de los hechos reales». ${ }^{.7}$ Con actitudes de este géne-

\footnotetext{
73 Einstein, Carl. Die Fabrikation der Fiktionen, op. cit., p. 54.

74 Ibidem, p. 193.

75 Ibidem, p. 285.

76 Ibidem, p. 195.

77 Cit. en Blanchot, Maurice. Los intelectuales en cuestión. Esbozo de una reflexión. Madrid: Tecnos, 2003 (trad. Manuel Arranz), p. 59.
} 
ro, elitistas o aviesas, según se quiera, se ampliaba a ojos vistas la distancia entre la realidad y su reflejo o entre lo crudo y lo cocido, y justamente en esa brecha venía a introducirse Die Fabrikation der Fiktionen como una cuña que buscase ensanchar la cesura y hacerla, a efectos denunciatorios, aún más visible.

\section{El frente ficticio-regresivo}

Si bien Einstein sitúa en su punto de mira los manejos genéricos del Privatkapitalismus y de la liberale Bourgeoisie -suyas son las expresiones-, lo cierto es que en esa época existía un colectivo que, ya fuera por incapacidad para encajar en la sociedad del momento, ya por temor a una pérdida definitiva del control sobre ella, no dudaría en abonarse a la creencia de que los límites de su entendimiento eran los del conocimiento en general y tamaña aporía sólo podía resolverse mediante una metódica intervención en los motores de cambio. El oxímoron revolución conservadora, en efecto, ha servido para aglutinar a esa contraparte de la Modernidad alemana abanderada por los Spahn, Schmitt, Spengler o Jünger que en pleno periodo de entreguerras actuaba como correlato intelectual del viejo poder guillermiano - los industriales y financieros, la aristocracia terrateniente, el ejército atávicamente antidemocrático, las iglesias protestante y católica, el aparato burocrático, las instituciones académicas-, un estamento al que venía a sumarse el inmenso y variopinto contingente formado por pequeños propietarios, burgueses asustadizos, desmovilizados carentes de empleo, jóvenes desnortados y todos aquellos a quienes la complejidad del mundo moderno, el resentimiento y la ausencia de expectativas enquistaba en posiciones reaccionarias. Aunque hay quien ha querido ver en Die Fabrikation der Fiktionen un artefacto dirigido a la línea de flotación de ese colectivo en relación con el entonces incipiente nazismo, ${ }^{78}$ es obvio que semejante lectura denotaría la existencia de una teleología restringida, y si bien Einstein está atento a un campo de maniobras donde se ensayan actitudes, argumentos y métodos que en mayor o menor medida acabarán incorporándose al arsenal nacionalsocialista, lo cierto es que su iniciativa tiene más de pasión que de cálculo y más de urgencia que de aliento visionario, no pareciendo apropiado añadir su nombre al listado de aquellos intelectuales que previeron la magnitud de la catástrofe en ciernes y que Enzo Traverso, sirviéndose de una expresión acuñada por Benjamin, bautizase como alertadores de incendio. 79

78 Cfr. Franke-Gremmelspacher, Ines. 'Notwendigkeit der Kunst?'. Zu den späten Schriften Carl Einsteins, op. cit., p. 92, e incluso, más recientemente, Berning, Matthias. Carl Einstein und das neue Sehen. Entwurf einer Erkenntnistheorie und politischen Moral in Carl Einsteins Werk. Würzburg: Königshausen \& Neumann, 2011, p. 259.

${ }^{79}$ Cfr. Traverso, Enzo. La historia desgarrada. Ensayo sobre Auschwitz y los intelectuales. Barcelona: Herder, 2001 (trad. David Chiner), pp. 38-43. 
De hecho, no está de más recordar que la revolución conservadora, tantas veces considerada como antesala del mal absoluto, no designa una ideología concreta sino una tendencia genérica cuyo fin es el desmantelamiento de los mecanismos reguladores de la Wirklichkeit: cuando Moeller van den Bruck establece en Der dritte Reich la primacía de la espiritualidad frente a la política convencional o Edgar J. Jung admite que, por encima todo, de lo que se trata es de hacer frente a la tradición ilustrada, salta a la vista que la máxima aspiración del movimiento es asumir el mando de la dinámica social con nuevos métodos. O no tan nuevos: "se comportaban como la policía de lo real (Polizei des Wirklichen)», ${ }^{80}$ subraya Einstein, «se querían liberar de la masa y mantenerla a raya», ${ }^{81}$ de ahí que la represión a pie de calle de toda divergencia les pareciese un modo natural de rescatar y salvaguardar los valores legítimos, a saber, los del antiguo régimen. Si bien su exclusivismo actuaba como encarnación de estructuras poco o nada adaptadas a la modernidad, lo cierto es que se ofrecía recubierto de un barniz subversivo al postularse como alternativa a los dictados igualitarios de la constitución de Weimar, de forma que, bajo la apariencia de una tercera vía ideal, la síntesis de inmovilismo y sedición que da nombre al movimiento se presentaba a sí misma como una venturosa Überwindung (superación) del conflicto que desgarraba a la nación alemana.

Tal y como estaba sucediendo en la Unión Soviética, «los intelectuales sostenían que a ellos les competía elaborar los modelos y utopías futuros», 82 con la notable diferencia de que las ensoñaciones conservadoras apenas pasaban de ser impúdicos rescates de un pasado ya fenecido. Así vendría a demostrarlo el producto más consumado de esta corriente, La decadencia de Occidente, de Oswald Spengler, oportunamente caracterizado por Eric D. Weitz como «un profundo compendio de Historia y Filosofía, pero plagado de contradicciones, de leyes no demostradas sobre el auge y la caída de culturas y civilizaciones, mediante el recurso arbitrario y caprichoso a las matemáticas y a las ciencias naturales como explicación del devenir de la Historia», de suerte que «se lee como si fuera un trabajo de un chiflado erudito o de un sabio necio».83 Acogiéndose a una larga tradición que desliga la Historia del control humano, si en semejante cadáver exquisito existe una constante es la concepción del proceso histórico como algo ni lineal, ni progresivo ni acumulativo sino puramente cíclico, análogo al funcionamiento de la naturaleza, luego no ha de extrañar que en estas circunstancias la recurrencia del daño social se manifieste como eugenesia y el inmovilismo de las estructuras de poder como un imponderable biológico. «La realidad histórica -apunta Einstein al respecto- fue expulsa-

\footnotetext{
80 Einstein, Carl. Die Fabrikation der Fiktionen, op. cit., p. 194.

81 Ibidem, p. 189.

82 Ibidem, p. 67.

83 Weitz, Eric D. La Alemania de Weimar. Presagio y tragedia. Madrid: Turner, 2009 (trad. Gregorio Cantera), p. 387.
} 
da por la mecánica ideal de ideologías carentes de realidad (wirklichkeitsarmen Ideologien)», 84 quedando justificada por sí sola toda intervención conservadora con su característico mantenimiento de las prerrogativas aristocráticas, su incondicional defensa de lo atávico, su justificación de la violencia en tanto que manifestación de las fuerzas del espíritu y su arraigado temor a los ritmos de la modernidad. «La supuesta repetición en la que se afirmaban los ideales velaba la dialéctica histórica» por la sencilla razón de que «si uno solamente girase en círculos sería absurdo desde un principio cualquier rebelión», 85 resuelve Einstein, y esa precisamente, la vieja doctrina de la predestinación y de la consiguiente inanidad de toda voluntad de cambio, ya fuera colectiva o individual, gradual o subitánea, era la enseñanza que se quería administrar. Los discursos de un Spengler o un Rosenberg -como en su día el de Baader o Hamann- sonaban tanto más convincentes cuanto más se postulaban a sí mismos como soluciones perentorias, cuanto más proponían lo ya sido, y no lo hipotético, como vía de escape frente a la extraordinaria complejidad del presente. Según el catecismo irracionalista, y al modo de una flor rebrotando de entre los escombros ocasionados por la benjaminiana tempestad del progreso, «el mito, que había sido expresión de la magia colectiva, debía salvar al individuo en una era tecnológica» ${ }^{86}$ puesto que prometía «un paraíso de inmortalidad ficticia e ilimitado retorno que hacía olvidar toda muerte». 87 De resultas de todo ello, la Wirklichkeit moderna, con su exigencia de compromiso cívico y su inherente mutabilidad, se veía enérgicamente sobrepujada por una Realität sostenida en Fiktionen -ya fueran leyendas fundacionales, tesis raciales o reinterpretaciones de tal o cual dogma espiritual- cuyo efecto analgésico proporcionaba a los individuos cierta estabilidad emocional y a la intelectualidad un aura taumatúrgica. Visto que «por medio de la regresión se intentaba liberar a la persona de la actualidad» 88 , Einstein no duda en concluir que «la primitivización indica una huida de la complejidad actual» 89 disfrazada de cruzada manumisora, siendo que conceptos como tradición, fe colectiva o espíritu nacional mantenían a raya el sindiós moderno a la vez que apuntalaban una casa común cerrada herméticamente, en el amplio sentido de la expresión.

\footnotetext{
84 Einstein, Carl. Die Fabrikation der Fiktionen, op. cit., p. 207.

85 Ibidem.

86 Ibidem, p. 67.

87 Ibidem, p. 203.

88 Ibidem, p. 106.

89 Ibidem, p. 54. Cómo no ver en esta imagen espectral el rostro de Gottfried Benn, con quien Einstein mantuvo en tiempos relaciones de amistad, colaboración y mutua influencia que se irían disipando al ritmo de los acontecimientos político-sociales y de las posiciones que cada uno adoptó en consecuencia. Sobre este aspecto, cfr. Siemon, Johann: «Einstein und Benn. Geschichte einer Entfernung?», en Kiefer, Klaus H. (ed.). Carl-Einstein-Kolloquium 1994. Bern/ Frankfurt a.M./ New York: Peter Lang, 1996, pp. 89-104, así como Meffre, Liliane. Carl Einstein 1885-1940. Itinéraires d'une pensée moderne. Paris: Presses de l’Université de Paris-Sorbonne, 2002, pp. 69-73.
} 
Bien se sabe a qué extremos acabaría llevando la consideración de la masa como simple reunión de individualidades ensoñadoras y del Privatkapitalismus como literal religión de bolsillo, aunque no está de más recordar que el atontamiento inducido no era un patrón exclusivo del liberalismo sino que en mayor o menor medida interesaba a sus supuestos oponentes en el arco político, léase una izquierda parlamentaria cuya mixtura de abstracción y pragmatismo tardaría poco en hacerla objeto de sospecha. ${ }^{90}$ En este sentido, la brutal represión ejercida por el gobierno del SPD (Sozialistische Partei Deutchslands) en los levantamientos de noviembre de 1918, donde Einstein cumpliera un papel nada desdeñable, se compadecía mal con la fraternidad obrera y dejaba al desnudo su peculiar "conciencia de clase", evidenciando una estrategia que Lukács denomina racionalidad realista como contraposición al supuesto aventurerismo irracional de una izquierda tachada de extrema: «la línea racional significa por tanto, prácticamente, para las masas: someterse y no declararse en huelga ante las rebajas de salarios, abstenerse de toda manifestación, de toda protesta y de toda reacción enérgica, ante los subsidios de paro forzoso o la supresión del derecho de subsidio para masas cada vez mayores de obreros, y ante las más sangrientas provocaciones del fascismo, ceder, replegarse, no defender la fuerza de la clase obrera y su derecho a dominar la calle». ${ }^{91} \mathrm{De}$ conformidad con este decálogo, mantener bajo control a la masa pasaría por instarla al abandono de toda esperanza revolucionaria mientras se operaba una desvirtuación de los derechos elementales -el derecho a la libertad venía a sustituirse por una optatividad restringida, el derecho a realizarse como individuo por un sucedáneo de personalidad-, y todo ello en el marco de una pragmática racionalidad que decía perseguir el bien común mediante su reducción a la mínima expresión. «El culto a la persona -apostilla Einstein- se fue solidificando a lo largo del tiempo; lo colectivo fue considerado obstaculizador, negativo» ${ }^{92}$, siguiendo la premisa de que, «cuanta mayor preeminencia adquiera la persona, tanto mayor la descomposición de los objetos concretos». $93 \mathrm{O}$ dicho de otro modo y retomando la consigna original: instigada y amparada por la política y la intelectualidad oficiales, la generación de ficciones se incrementaba de forma directamente proporcional a la destrucción de aquella realidad que decían referir.

\footnotetext{
90 Algo que sucedería, en el caso de Einstein, bien pronto: ya en un artículo aparecido en 1914 en la revista Die Aktion arremete contra «los socialdemócratas, esta dictadura del ser político [que] evoluciona de protesta en protesta hasta que mediante un conjunto de colaboradores asienta su teoría. Una asociación de racionalistas nunca revolucionará nada; si acaso, lo ordenará». Einstein, Carl. «Die Sozialdemokratie», en Einstein, Carl. Werke. Berliner Ausgabe, Band I. 1907-1918 (Hermann Haarmann, Klaus Siebenhaar eds.). Berlin: Fannei \& Walz, 1994, p. 213.

${ }^{91}$ Lukács, Georg. El asalto a la razón. Barcelona: Grijalbo, 1976 (trad. Wenceslao Roces), p. 65.

92 Einstein, Carl. Die Fabrikation der Fiktionen, op. cit., p. 151.

93 Ibidem, p. 306.
} 


\section{Ensimismamientos y malas artes}

Einstein ve en esa depreciación de la existencia operada por el pensamiento triunfante el paradigma de la crisis, y forzoso es reconocer que llega a los límites de paroxismo al hacer extensiva la responsabilidad en la catástrofe a aquellas disciplinas que, independientemente de su conexión con el idealismo liberal, comparten con él la creación de formulaciones alejadas de lo real sensible. Según dicta su silogismo, si «en cada formulación abstracta se esconde una tendencia nihilista», 94 entonces todo cuanto suponga un sistema referencial o siquiera una elaboración mínima a partir de lo real atentará contra sus agentes y contra el mundo en sí. No parece claro qué alternativa puede proponer el ser humano a dichas "formulaciones abstractas", ya sean científicas, filosóficas, lingüísticas o estéticas, pero el caso es que un Einstein fuertemente agresivo -y tan nihilista como aquello que tilda de talarremete contra todas ellas alegando su común alejamiento con respecto a la realidad y, por tanto, la consiguiente devaluación de fenómenos y hechos -los antedichos Ereignis (suceso) y Tatsache (hecho)- que llevan aparejada. En el fondo, cuando su desquiciamiento le lleva a denunciar que los filósofos «creaban reservados teóricos, donde ya no encajaban los momentos y los vínculos concretos» ${ }^{95}$ y que «utilizaban esta encantadora herramienta para depreciar la experiencia concreta e inequívoca de los hombres inocentes», 96 lo que está censurando, una vez más y con tesis similares a las conocidas, es el aciago viraje de una objetividad colectiva a una objetividad subjetiva, el desplazamiento de una conciencia común a un personalismo investido de inmanencia. Es más: al escamotear el carácter artificioso de ese corpus teórico se estaría induciendo una mayúscula confusión entre la evaluación de lo fáctico y su reelaboración, entre lo empírico y lo facultativo, promiscuidad que en último extremo convertiría en virtualmente idénticas la actividad filosófica y la poética. Einstein:

El filósofo abjura de lo real (vom Wirklichen) y sitúa en su lugar las hipótesis ideales [...] De hecho ya no puede hablarse de conocimiento sino de una poesía pedante y especializada [...] Tocamos la analogía entre la filosofía idealista y la poesía. Aquí gira la cadena de los conceptos imprecisos e irreales, allí sigue una metáfora, a través de la cual la certeza actual queda desconectada de todo lo demás. En ambos casos se constata un automatismo alucinatorio que se hace posible mediante la eliminación de lo concreto, en ambos casos se capta la anestesia visionaria y estética, en ambos casos está sujeto el hombre a una hipnosis arcaica. ${ }^{97}$

\footnotetext{
94 Ibidem, p. 306.

95 Ibidem, p. 57.

96 Ibidem, p. 44.

97 Ibidem, p. 214.
} 
No deja de ser significativo que justamente en esos mismos momentos, y en la misma ciudad en la que Einstein da forma a su texto, otro intelectual esté dando cauce a su desencanto en parecidos términos y con similares argumentos. Paul Nizan, en efecto, se sitúa bien cerca de los presupuestos einsteinianos cuando sentencia en Les chiens de garde que la filosofía es «una entidad del discurso» 98 cuyo cometido no es tanto servir al avance del pensamiento cuanto, bien al contrario, sancionar el ensimismamiento académico y apuntalar el sistema de valores del aparato liberal. Los «filósofos confortables» ${ }^{99}$-así Brunschvicg y Bergson, por mencionar solo a dos de los demonios de Nizan- «forjan la teoría de la práctica burguesa, forjan la metafísica del universo que el burgués desea» $100 \mathrm{y}$, de esta suerte, «sustituyen por revelaciones o procesos ocultos las formaciones concretas».101 El burgués medio, remacha Nizan con palabras que Einstein podría haber pronunciado, queda atrapado «en medio de sus sustituciones, de sus metamorfosis, de esas tramas de espejismos que ellos tienden», 102 de «productos teratológicos de la meditación» 103 que, lejos de servirse del mundo para revertir después en él, son fruto de un abandono a la especulación y a la mera fantasía. La cerrada defensa del materialismo hace caer a Nizan en fórmulas retóricas -alguno diría demagógicas - de tintes eminentemente einsteinianos, como cuando afirma que «hay, de una parte, la filosofía idealista que anuncia verdades sobre el hombre, y de la otra el mapa de la distribución de la tuberculosis en París que habla de cómo mueren los hombres», 104 o cuando subraya el papel estratégico que cumpliría ese idealismo:

toda esta filosofía sirve para cubrir con un velo las miseria de la época [...] Sirve para apartar a los explotados de la contemplación, peligrosa para los explotadores, de su degradación, de su sometimiento. Tiene por misión lograr que se acepte un orden haciéndolo amable, confiriéndole nobleza, aportándole justificaciones. Mistifica a las víctimas del régimen burgués, a todos los hombres que podrían alzarse contra él. Los dirige hacia vías muertas donde la revuelta se apaga. Sirve a la clase social que es causa

\footnotetext{
98 Nizan, Paul. Les chiens de garde. Marseille: Agone, 1998, p. 22. Amén de similitudes en la forma y el contenido, bastante hay de malditismo en la peripecia de ambos textos: si Die Fabrikation der Fiktionen permanecería inédito durante larguísimo tiempo, Les Chiens de garde -título que venía a sustituir al que, de acuerdo con el contrato editorial, había previsto Nizan, Discours aux jeunes hommes- se publica en 1932 pero no alcanza ni de lejos el eco previsto. Emmanuel Berl y Gabriel Marcel se cuentan entre los pocos reseñistas que ven elementos de valor en un ensayo cuya acritud suscita el silencio de los antiguos compañeros de Nizan en la École normale superiéure de París, Jean Paul Sartre y Raymond Aron, cuando no un abierto rechazo, especialmente agudo en la persona de André Gide. 99 Ibidem, p. 61.

100 Ibidem, p. 66.

101 Ibidem, p. 37.

102 Ibidem, p. 86.

103 Ibidem, p. 44.

104 Ibidem, p. 26.
} 
de todas las degradaciones presentes, la misma clase de la que los filósofos forman parte. 105

Salta a la vista que Nizan no escatima recursos a la hora de hacer frente a los responsables de ese estado de cosas que se ha dado en llamar lo que hay, y de hecho, al igual que sucede con Die Fabrikation der Fiktionen, «aquello que Les chiens de garde conserva de mejor hoy día -opina Pascal Ory- es lo que el panfleto tiene de 'libro individual', de ajuste de cuentas personal», ${ }^{106}$ sobre todo tomando en cuenta que «no estaba destinado a conquistar a las masas» 107 sino a agitar determinadas conciencias académicas. Sin embargo, y en abierto contraste en este punto, el desquite de Einstein trasciende el ámbito de las "artes del pensamiento" para extenderse al marco literario y mucho más allá, pues si bien consagra de forma casi específica dos secciones de la obra - "Buch III: Das Vacuum" y "Buch IV: Sonderbild"a desmontar con tanto pormenor como su metodología permite los manejos de aquellos escritores que «mantenían una oposición estética hacia lo real (Wirklichen)», 108 lo cierto es que prestará una especial atención a otro núcleo cultural, el de las artes plásticas, que conoce de primerísima mano.

En el establecimiento de la secuencia que acabará conduciendo a Einstein al anarquismo armado los ataques de Die Fabrikation der Fiktionen hacia la institución artística constituyen sin duda un hito clarificador. Visto lo visto, y como era de esperar, el balance que del arte del momento se hace en el escrito es consecuencia del establecido a cuenta de la actividad intelectual en general, siendo que «el criterio de este arte era la destrucción consumada de lo real» ${ }^{109}$ y no ya su arbitraje o su regeneración. Hasta hacía poco el ser humano consideraba crucial la mediación artística pese a su inherente precariedad o, por mejor decir, merced a ella, pues precisamente «gracias a las carencias de la expresión artística pueden diferenciarse la obra de arte y la realidad», 110 pero la progresiva desnaturalización de dicha expresión habría desembocado en un desencuentro tan fatal como sus consecuencias, a saber, sumaria destitución de la Wirklichkeit y subsiguiente introversión de un arte que ya no creía necesario rendir cuentas a nadie. "Ahora los artistas especializados desarrollaban la técnica y parloteaban acerca del arte como fin en sí mismo; con esa palabra clave se constataba que el arte había perdido su sentido», 111 circunstancia donde sitúan su origen «el baile de espíritus de la transformación estética (síntoma

\footnotetext{
105 Ibidem, pp. 107-8.

106 Ory, Pascal. Nizan. Destin d'un revolté. Bruxelles: Complexe, 2005, p. 88.

107 Ibidem, p. 91.

108 Einstein, Carl. Die Fabrikation der Fiktionen, op. cit., p. 240.

109 Ibidem, p. 58.

110 Ibidem, p. 289.

111 Ibidem, p. 54.
} 
de la crisis del mundo)»112 y «el campeonato de la originalidad», 113 idéntico hasta en los más mínimos detalles al disputado en el seno del mercantilismo capitalista. En plena sintonía con el comportamiento de los intelectuales, más sectarios que participativos, más obcecados en la reivindicación de una parcela en el Parnaso que en la del ahora y aquí mismo, los artistas dieron en crear «metáforas inverificables»114, y así como la revolución conservadora se servía de una retórica arcana y el liberalismo triunfante de conceptos dotados de escasa comprensión autónoma que comunicaban más a través de la propia opacidad que de cualquier contenido, así ellos «impugnaron el condicionamiento histórico y social del arte e intentaron crear realidades extraordinarias de uso exclusivo», 115 «existencias privadas». 116 De resultas de todo ello «se rompió el puente entre la obra de arte y las vivencias comunes»y, pírrica victoria del arte moderno, gloria y miseria tantas veces señalada, «las obras de arte se entumecieron como creaciones aparentemente autónomas». ${ }^{117} \mathrm{Al}$ entregarse a ensoñaciones de toda índole o a un primitivismo que respondía más a los dictados del capricho que a una heurística funcional, el arte habría saltado los goznes que le unían a su propio tiempo. Seducido por las circunstancias que decía combatir, nimbado de un resplandor revolucionario ya puramente ornamental, «difícilmente puede el arte moderno llegar a insertar una estructura socialmente modificada» cuando sus artífices «viven en un aristocrático feudalismo primigenio»118, resuelve un Einstein que en tiempos lo había fiado todo a la Vanguardia y ahora la repudiaba a causa de una deriva conservadora a la que apenas habría escapado aquel Picasso a quien dirigiera una de sus últimas cartas. A fuerza de demolición, incluyendo la de los propios agentes, ya nada se mantenía en pie.

\section{Conclusiones}

Acosado por el aparato ficcional nacionalsocialista, que con el inicio de las hostilidades había convertido ensoñaciones y juegos retóricos en la más cruda Wirklichkeit, un Einstein anarquista, excombatiente republicano y judío que se sabía tres veces condenado se quitaba la vida a comienzos de julio de 1940 cerca de Pau, dejando tras de sí numerosos escritos inconclusos o inéditos. Quizá quepa convenir con los editores de las obras completas de Carl Einstein en que Die Fabrikation der

\footnotetext{
112 Ibidem, p. 127.

113 Ibidem, p. 250.

114 Ibidem, p. 66.

115 Ibidem, p. 112.

116 Ibidem, p. 75.

117 Ibidem, p. 316.

118 Ibidem, pp. 252-3.
} 
Fiktionen «en ningún caso provoca una reorientación fundamental del pensamiento einsteiniano» 119 , habida cuenta de la coherencia ideológica que mantuviera a lo largo de toda su vida, aunque sí un cambio procedimental que le llevaría de la actividad intelectual ejercida en soledad a la acción directa desplegada de forma colectiva y, en último término, cuando la utopía revolucionaria española se viniese abajo, a apagar la luz. Independientemente de si constituye un intento de autoposicionamiento o una llamada a la lucha activa, el texto es un desesperado alegato materialista y una feroz crítica al pensamiento especulativo en un momento histórico que no admitía ni pasividades ni medias tintas. Un momento que se prolongaría, valga la fórmula, en el tiempo: cuando más tarde los integrantes del Instituto de Investigación Social pongan el acento en los peligros del carrusel capitalista y en su vinculación con el aparato totalitario, o en el instante mismo en que la obra vea finalmente la luz -ese 1974 en el que las fuertes fricciones ideológicas y el activismo armado conmocionan a la sociedad europea-, Die Fabrikation der Fiktionen acabará encontrando retroactivamente un destellante e inopinado sentido. También hoy, sobra decirlo, cuando la fábrica de ficciones de la democracia procedimental sigue funcionando a pleno rendimiento.

José María de Luelmo Jareño

Departamento de Pintura

Universitat Politècnica de València

jolueja@pin.upv.es

119 Haarmann, Hermann; Siebenhaar, Klaus. "Editorische Notiz", en Einstein, Carl. Werke. Berliner Ausgabe, Band III. 1929-1940, op. cit., p. 11. 